\title{
Salivary profile of children with erosive tooth wear: a transversal study
}

\author{
Caleb SHITSUKA(a) \\ Luiz Felipe PALMA ${ }^{(b)}$ (iD \\ Irineu Gregnanin PEDRON(c) \\ Tatiana Geraldo Guizelini POLOTOW(d) \\ Marcelo Paes de BARROS(d) (D) \\ Mariana Ferreira LEITE ${ }^{(e)}$ \\ Maria Salete Nahás Pires CORRÊA ${ }^{(f)}$ \\ (a)Faculdades Metropolitanas Unidas - FMU, \\ School of Dentistry, São Paulo, SP, Brazil. \\ (b) Universidade Ibirapuera - UNIB, Graduate \\ Dentistry Program, São Paulo, SP, Brazil. \\ (c) Universidade Brasil - UB, School of \\ Dentistry, São Paulo, SP, Brazil. \\ (d) Universidade Cruzeiro do Sul - Unicsul, \\ Institute of Physical Activity and Sport \\ Sciences, Postgraduate Program in Human \\ Movement Sciences, São Paulo, SP, Brazil. \\ (e) União Metropolitana de Educação e Cultura \\ - Unime, Shoool of Dentistry, Salvador, \\ BA, Brazil. \\ (f) Universidade de São Paulo - USP, School of \\ Dentistry, Department of Pediatric Dentistry, \\ São Paulo, SP, Brazil.
}

Declaration of Interests: The authors certify that they have no commercial or associative interest that represents a conflict of interest in connection with the manuscript.

Corresponding Author:

Luiz Felipe Palma

E-mail: luizfelipep@hotmail.com

hitps://doi.org/10.1590/1807-3107bor-2020.vol34.0115

Submitted: February 17, 2020

Accepted for publication: July 10, 2020

Last revision: July 31, 2020
Abstract: The aim of the present transversal study was to evaluate the clinical and biochemical salivary parameters of children with and without erosive tooth wear (ETW). The study population was children aged 4 to 9 years. A trained and calibrated examiner (kappa value for intraexaminer reliability $=0.89$ ) classified the children into ETW $(n=24)$ and control groups $(n=24)$, and applied the O'Brien index. The salivary flow rate was initially evaluated by stimulated sialometry (paraffin chewing). Afterwards, the collected saliva was submitted to biochemical analyses of $\mathrm{pH}$, uric acid, total buffering capacity, ferric-reducing antioxidant power, reduced glutathione, calcium, and phosphorus. Among the ETW children, 20 (83\%) had dental lesions restricted to enamel, and $4(17 \%)$ presented lesions affecting both enamel and dentin. A statistically significant difference between the groups was obtained only for the $\mathrm{pH}$ values (t-test; $\mathrm{p}=0.004$ ), with averages of 7.31 and 7.56 for the control and the ETW groups, respectively. Considering the parameters evaluated in general, it is suggested that the salivary profile of children with ETW does not differ considerably from that of children without ETW. However, the $\mathrm{pH}$ mean value seems to be slightly higher in ETW children, but is still within the normal physiological range.

Keywords: Tooth Erosion; Saliva; Pediatric Dentistry.

\section{Introduction}

Erosive tooth wear (ETW) affects dental mineralized tissues, and is considered a complex and multifactorial oral health problem. ${ }^{1}$ It is defined as a chemical-mechanical process caused mainly by acid aggression not related to bacteria. ${ }^{2}$ The acid challenge may be of either intrinsic (e.g., gastric acid) or extrinsic origin (e.g., dietary habits), ${ }^{3}$ and the etiology directly influences the pattern of dental damage. ${ }^{4}$

Overall, ETW prevalence ranges considerably worldwide, recording rates between 0 and $100 \%$, based on studies from different countries and populations. ${ }^{5}$ Owing to current lifestyle changes, ${ }^{6}$ and the specific features of primary teeth (e.g. lower mineral levels in enamel $)^{7}$ and saliva, ${ }^{8,9}$ children seem to be more prone to ETW today. ${ }^{10}$ A systematic review reported a prevalence rate between 0 and $82 \%$ of ETW involving the dentin in the primary teeth of children up to 6.5 years, and between 0 and $54 \%$ in the permanent teeth of children older than 7 years. ${ }^{11}$ Despite 
the high prevalence, ETW is found in children mainly in its early stages, which affect only the tooth enamel.1,13,14

Since ETW usually leads to loss of the morphology of dental surfaces, ${ }^{2}$ these erosive lesions are diagnosed by visual inspection of their morphological features; however, diagnosis is possible only when there is considerable loss of mineralized structure. ${ }^{15}$ Although it is very common, ETW becomes a concern only in advanced stages, which affect aesthetics, and lead to functional impairment and dentin hypersensitivity., ${ }^{6,16}$ Dentists seek to keep ETW at bay, usually by implementing preemptive measures, which involve using fluorides, recommending oral hygiene practices, and giving dietary counseling. ${ }^{6}$

Saliva is an essential factor for oral health. ${ }^{17}$ It protects the teeth against ETW in different ways, mostly by: a) acting directly on acid substances, by diluting, clearing, neutralizing, and buffering acids; b) participating in pellicle formation; c) providing calcium, phosphate, and fluoride for the remineralization process. ${ }^{18}$ Although the oral antioxidant system has not yet been fully elucidated, saliva seems to play an important role. This highly complex system is composed of many factors and processes, and may cause cell damage followed by cell death, leading to a decreased formation of dental biofilm, which is also considered a protective mechanical barrier against ETW. ${ }^{19}$

The number of investigations conducted on ETW has increased significantly in recent years; however, too little is known about the salivary profile in children with this condition. In light of this need, the study tested the hypothesis that children with ETW would present alterations in some salivary features, leading to higher susceptibility to ETW. The present study aims at investigating this hypothesis by evaluating clinical and biochemical salivary parameters of children with and without ETW.

\section{Methodology}

\section{Study design and ethical issues}

This transversal study was previously approved by the Research Ethics Committee of Universidade Cruzeiro do Sul (Protocol \#015/2010), and included a convenience sample of 48 children aged 4 to 9 years who attended the Pediatric Dentistry Clinic at Universidade Cruzeiro do Sul (São Paulo, SP, Brazil) in 2010.

All participants met the following inclusion criteria: good general health, no intake of medication that would alter salivary flow/composition, and no inflammatory/infectious oral condition.

Before being submitted to any procedure, the patients received information on the study, together with their parents. The caregivers of those who agreed to participate read and signed the informed consent form.

\section{ETW diagnosis}

A trained and calibrated examiner diagnosed ETW, after having previously undergone 2 sessions (4 hours each session) of diagnostic exercises, with 20 clinical images and 20 extracted teeth (varying degrees of wear), for ETW identification. The kappa test for intraexaminer reliability was 0.89 .

The examiner ensured correct diagnosis of ETW in the study sample by performing relative isolation (cotton rolls, saliva ejector, and air-jet drying), and using dental mirror \#5.

The children were divided into two similar groups, according to the presence of ETW on at least one tooth surface: control $(n=24)$ and ETW $(n=24)$ groups. The $\mathrm{O}^{\prime}$ Brien index ${ }^{20}$ was used to evaluate ETW severity.

\section{Stimulated sialometry}

Sialometry tests were performed on all children from 3 p.m. to 5 p.m. to prevent physiological changes influenced by the circadian rhythm. They were advised to refrain from eating, drinking, or brushing their teeth two hours before the procedures. They remained seated, with their eyes open and heads bent slightly forward during saliva collection.

The children were asked to chew on a tasteless and odorless piece of paraffin $(3 \mathrm{~cm} \times 3 \mathrm{~cm}, 0.7 \mathrm{~g})$ for a total of 6 minutes. The saliva secreted in the first minute was swallowed. That accumulated on the floor of their mouth in the remaining 5 minutes was expectorated into a graduated tube fitted with a funnel. The salivary flow rate was calculated in milliliters per minute ( $\mathrm{mL} / \mathrm{min})$. 
The tubes containing saliva samples were kept in ice for a short period (transportation) and then stored at $-80^{\circ} \mathrm{C}$ in order to preserve their features.

\section{pH}

The $\mathrm{pH}$ analysis was performed with an UltraBasic UB-10 digital portable $\mathrm{pH}$ meter (Denver Instrument, Bohemia, NY, USA). The device was calibrated by placing the electrode into two different solutions with known $\mathrm{pH}$ values, according to the manufacturer's instructions.

\section{Buffering capacity}

Buffering capacity was determined by titration with a $0.01 \mathrm{~N} \mathrm{HCl}$ solution.

A $0.2 \mathrm{~mL}$ aliquot of $0.01 \mathrm{~N} \mathrm{HCl}$ was added to $1 \mathrm{~mL}$ salivary samples, and the same digital portable $\mathrm{pH}$ meter was used to check the $\mathrm{pH}$. This process was repeated constantly until the value of $\leq 5.5 \mathrm{pH}$ was obtained.

\section{Uric acid}

Uric acid was quantified using a specific biochemical kit (BioClin Quibasa, Belo Horizonte, Brazil).

Uric acid is oxidized by uricase, forming allantoin and $\mathrm{H}_{2} \mathrm{O}_{2}$, which reacts with 4-aminoantipyrine and 3,5-dichloro-2-hydroxybenzene sulfonate in a peroxidase-catalyzed reaction. The product from this reaction could then be quantified using a spectrophotometer at a $520 \mathrm{~nm}$ wavelength. ${ }^{21}$

\section{Ferric-reducing antioxidant power (FRAP)}

FRAP was analyzed according to a previous study ${ }^{21}$ based on modifications of the method originally described by Benzie and Strain. ${ }^{22}$ Changes included replacement of the $\mathrm{Fe}^{2+}$-chelating agent 2,4,6-tri(2-pyridyl)-s-triazine by its analog agent 2,3-bis(2-pyridyl)-pyrazine (DPP). ${ }^{23}$ In brief, the reactant mixture for the FRAP assay contained $10 \mathrm{mM}$ DPP (stock solution prepared in $40 \mathrm{mM} \mathrm{HCl}$ ) and $20 \mathrm{mM} \mathrm{FeCl}_{3}$ in $0.30 \mathrm{M}$ acetate buffering solution (pH 3.6). A $10-20 \mu \mathrm{L}$ sample was added to $200 \mu \mathrm{L}$ of the FRAP reactant mixture, together with $40-30 \mu \mathrm{L}$ distilled water (total volume, $250 \mu \mathrm{L}$ ). Absorbance at $593 \mathrm{~nm}$ was recorded for 4 minutes to determine the rate of $\mathrm{Fe}^{2+}$-DPP complex formation, compared with a standard curve.

\section{Reduced glutathione (GSH)}

The GSH level in saliva was measured as described by Rahman et al..$^{24}$ The method is based on the reaction between reduced thiol groups with 5.5'-dithiobis-2- nitrobenzoic acid (DTNB) to form 5-thio-2nitrobenzoic acid (TNB), which is stoichiometrically detected by absorbance at $412 \mathrm{~nm}$. Purified GSH was used as the standard sample.

\section{Calcium}

Calcium was determined according to a method proposed by Ferro and Ham. ${ }^{25}$ Salivary calcium was precipitated using chloranilic acid, to yield calcium chloranilate, which was then washed in 50\% isopropyl alcohol, and dissolved in a 5\% ethylenediaminetetraacetic acid (EDTA) aqueous solution. Calcium phosphate $(0.1 \mathrm{mg} / \mathrm{mL})$ was then used as the standard sample to calculate the calcium concentration, using a spectrophotometer at $520 \mathrm{~nm}$.

\section{Phosphorus}

Phosphorus was evaluated based on a method described by Fiske and Subarrow. ${ }^{26}$ Saliva samples had to be deproteinized by incubation with $1.2 \mathrm{M}$ trichloroacetic acid (TCA), to allow the phosphorus minerals to react with molybdic acid $(2.5 \%$ ammonium molybdate solution in $10 \mathrm{~N}$ sulfuric acid) and form a complex of phosphomolybdic acid. This complex was then reduced by ascorbic acid to form a blue complex, in which the color intensity was proportional to the amount of inorganic phosphorus. The standard curve was determined by spectrophotometry at $720 \mathrm{~nm}$, using a $1 \mathrm{Mmol} / \mathrm{mL}$ standard phosphorus solution.

\section{Statistical analysis}

The data were tabulated into Microsoft Office Excel $^{\mathrm{TM}}$ spreadsheets (Microsoft, USA), and analyzed both descriptively and inferentially using Stata 9.0 (StataCorp LP, USA) software. The KolmogorovSmirnov test was used to check data distribution, and Levene's test, to examine variance equality. The 
Table. Averages, standard deviations ( \pm ), and effect size (d) of each salivary evaluation.

\begin{tabular}{|c|c|c|c|c|}
\hline \multirow{2}{*}{ Variable } & \multicolumn{2}{|c|}{ Group } & \multirow{2}{*}{$d$} & \multirow{2}{*}{$\mathrm{p}$-value } \\
\hline & Control & Erosive tooth wear & & \\
\hline Salivary Flow Rate (mL/min) & $0.52( \pm 0.34)$ & $0.60( \pm 0.26)$ & 0.26 & 0.366 \\
\hline Calcium $(\mu \mathrm{g} / \mathrm{mL})$ & $183.92( \pm 47.88)$ & $195.25( \pm 59.63)$ & 0.21 & 0.472 \\
\hline Phosphorus (mg/mL) & $1177.44( \pm 261.17)$ & $1141.98( \pm 327.10)$ & 0.12 & 0.680 \\
\hline $\mathrm{pH}$ & $7.31( \pm 0.30)$ & $7.56( \pm 0.28)$ & 0.86 & $0.004^{*}$ \\
\hline FRAP ( $\mu \mathrm{mol} \mathrm{Fe} / \mathrm{min} \mathrm{mL})$ & $1.44( \pm 1.04)$ & $1.44( \pm 1.12)$ & 0.0 & 0.991 \\
\hline Uric Acid (mg/dL) & $30.35( \pm 16.80)$ & $23.33( \pm 11.44)$ & 0.49 & 0.097 \\
\hline GSH (mM) & $0.08( \pm 0.05)$ & $0.13( \pm 0.12)$ & 0.54 & 0.121 \\
\hline Total Buffering Capacity (mL HCl $0.01 \mathrm{~N}$ ) & $1.23( \pm 0.32)$ & $1.41( \pm 0.35)$ & 0.54 & 0.076 \\
\hline
\end{tabular}

*Statistically significant difference (independent t-test, $p<0.05$ ).

differences between both groups were analyzed by the independent t-test, and Cohen's $d$ effect size was presented for all variables. The level of significance was set at $5 \%$.

The observed power for each parameter was calculated using $\mathrm{G}^{*}$ Power 3.197 ${ }^{\mathrm{TM}}$ software (Universität Kiel, Germany), adopting $\alpha=0.05$, as follows: salivary flow rate, $23 \%$; calcium, $18 \%$; phosphorus, $11 \%$; $\mathrm{pH}, 90 \%$; FRAP, 5\%; uric acid, 51\%; GSH, 58\%; total buffering capacity, $57 \%$.

\section{Results}

The mean age and standard deviation ( \pm ) of ETW and control groups were 7.56 years $( \pm 0.29)$ and 7.31 years $( \pm 0.30)$, respectively. According to the $\mathrm{O}^{\prime}$ Brien index, 20 (83\%) ETW children had dental lesions restricted to enamel and $4(17 \%)$ presented with lesions affecting both enamel and dentin.

There was no statistically significant difference between the groups regarding the salivary evaluation, except for the $\mathrm{pH}$ mean value, which was slightly higher in the ETW children's group. The data from each salivary evaluation are presented in Table, as well as detailed information on the statistical analyses.

\section{Discussion}

The aim of the current study was to evaluate certain salivary parameters used to identify alterations that would make children more likely to present ETW; however, a marked contrast was observed between its findings and the data from the literature, thereby making it difficult to draw definitive conclusions in this respect.

Regarding the characteristics of the sample, some epidemiological studies have encountered a high frequency of ETW in children, but generally in its early stage, i.e., lesions restricted to tooth enamel..$^{12,13,14} \mathrm{In}$ fact, evaluation by the $\mathrm{O}^{\prime}$ Brien index indicated that a large part of the ETW group had early-stage lesions. ${ }^{20}$

It is important to highlight that the mean $\mathrm{pH}$ of both groups can be considered normal (6.5-7.5), ${ }^{27}$ but that children with ETW presented a slightly higher value, a result that differs from others in the literature. ${ }^{19,28}$ Although the current finding seems to be contradictory, it raises the hypothesis that the basal salivary $\mathrm{pH}$ may increase in response to constant exposure to acid agents. To the best of the authors' knowledge, however, there is no evidence to support this.

In line with other studies on children and adolescents, ${ }^{19,28,29}$ no difference was seen in the total salivary buffering capacity between the groups. This salivary capacity is based on phosphate, carbonic acid, and bicarbonate systems, which regulate the oral $\mathrm{pH} .{ }^{30}$ Some authors, however, have asserted that a combination of individual factors (e.g., buffering capacity and salivary flow rate), along with chemical agents, may determine the risk of developing ETW and lesion severity.

Considering the lower salivary flow rate in the deciduous versus permanent dentition, ${ }^{19}$ the current 
findings corroborate other research results that have found no relationship between the quantity of saliva and ETW. ${ }^{19,28}$ On the other hand, a study with adolescents reported a reduced salivary flow rate in individuals with ETW. ${ }^{29}$

Some protective mechanisms are of paramount importance to prevent hard tissue dissolution during an erosive challenge, such as the common ion effect brought about by salivary calcium and phosphate. ${ }^{15}$ Furthermore, some peptides and proteins from saliva may bind to the calcium and phosphate on the tooth surface, contributing to the formation of salivary pellicle, which acts as an ion reservoir and partially protects the enamel surface from acidic attack. ${ }^{31}$ Although some authors have not found any association between salivary ion content and susceptibility to ETW, ${ }^{31}$ certain calcium and phosphorus concentrations have been investigated herein. As in other studies with 12-to-13-year-old children and adolescents, ${ }^{28,29}$ no difference was observed.

Shitsuka et al. ${ }^{19}$ reported less biofilm in children with ETW than in the controls, but observed no difference in regard to the activity of oxidative stress in saliva. These results corroborate the present findings, which show no differences in the non-enzymatic parameters for FRAP, GSH, and uric acid, all of which have specific antioxidant proprieties. ${ }^{32}$ These parameters were singled out for the current study because the FRAP test quantifies both the ability of saliva to chelate and the inactivate metal ions (mainly $\mathrm{Fe}^{2+} / \mathrm{Fe}^{3+}$ ) involved in oxidative stress; GSH is considered a biomarker of oxidative stress; and uric acid acts as a preventive antioxidant and a scavenger of free radicals that cause oxidative damage. ${ }^{21}$
Given the lack of sufficient evidence supporting the salivary profile in children with ETW, the results of this study are still a relevant contribution to the literature; however, they should be interpreted with caution. In regard to study limitations, some issues should be pointed out. First, a priori sample size estimation was not considered, which may have influenced the results, especially the likelihood of failing to detect true differences between the groups (type-2 error). Taking into account that the statistical power and $P$-values depend both on the size of the effect and the sample size, ${ }^{33}$ the convenience sample used herein probably did not provide sufficient power to detect statistical differences between both groups, as noted by the (post hoc) power calculated for each parameter.

The cut-off point used to allocate the children into the groups (i.e., at least one surface presenting ETW) is another potential study limitation, since it might have made the whole sample more homogeneous, and less prone to presenting the salivary parameter discrepancies between both groups. Therefore, more research focusing on the classification of children according to ETW stages is needed, with more in-depth information on the grouping adopted.

\section{Conclusion}

Within the limitations of this study, and considering the parameters evaluated, the findings seem to suggest that the salivary profile of children with ETW does not differ considerably from that of children without ETW. However, the $\mathrm{pH}$ mean value seems slightly higher in ETW children, but is still within the normal physiological range.

\section{References}

1. Marqués Martínez L, Leyda Menéndez AM, Ribelles Llop M, Segarra Ortells C, Aiuto R, Garcovich D. Dental erosion: etiologic factors in a sample of Valencian children and adolescentes: cross-sectional study. Eur J Paediatr Dent. 2019 Sep;20(3):189-93.

2. Carvalho TS, Baumann T, Lussi A. Does erosion progress differently on teeth already presenting clinical signs of erosive tooth wear than on sound teeth? An in vitro pilot trial. BMC Oral Health. $2016 \mathrm{Jul} ; 17(1): 14$. https://doi.org/10.1186/s12903-016-0231-y

3. Frazao JB, Machado LG, Ferreira MC. Dental erosion in schoolchildren and associated factors: A cross-sectional study. J Indian Soc Pedod Prev Dent. 2018 Apr-Jun;36(2):113-9. https://doi.org/10.4103/JISPPD.JISPPD_1041_17 
4. Friesen LR, Bohaty B, Onikul R, Walker MP, Abraham C, Williams KB, et al. Is histologic esophagitis associated with dental erosion: a cross-sectional observational study? BMC Oral Health. 2017 Aug;17(1):116. https://doi.org/10.1186/s12903-017-0408-z

5. Schlueter N, Luka B. Erosive tooth wear - a review on global prevalence and on its prevalence in risk groups. Br Dent J. 2018 Mar;224(5):364-70. https://doi.org/10.1038/sj.bdj.2018.167

6. Shitsuka C, Mendes FM, Corrêa MS, Leite MF. Exploring some aspects associated with dentine hypersensitivity in children. ScientificWorldJournal. 2015;2015:764905.

7. Wilson PR, Beynon AD. Mineralization differences between human deciduous and permanent enamel measured by quantitative microradiography. Arch Oral Biol. 1989;34(2):85-8. https://doi.org/10.1016/0003-9969(89)90130-1

8. Carvalho TS, Baumann T, Lussi A. In vitro salivary pellicles from adults and children have different protective effects against erosion. Clin Oral Investig. 2016 Nov;20(8):1973-9. https://doi.org/10.1007/s00784-015-1703-1

9. Anderson P, Hector MP, Rampersad MA. Critical pH in resting and stimulated whole saliva in groups of children and adults. Int J Paediatr Dent. 2001 Jul;11(4):266-73. https://doi.org/10.1046/j.1365-263X.2001.00293.x

10. Duangthip D, Chen KJ, Gao SS, Lussi A, Lo EC, Chu CH. Erosive tooth wear among preschool children in Hong Kong. Int J Paediatr Dent. 2018 Dec;29(2):185-92. https://doi.org/10.1111/ipd.12457

11. Kreulen CM, Van 't Spijker A, Rodriguez JM, Bronkhorst EM, Creugers NH, Bartlett DW. Systematic review of the prevalence of tooth wear in children and adolescents. Caries Res. 2010;44(2):151-9. https://doi.org/10.1159/000308567

12. Abanto J, Shitsuka C, Murakami C, Ciamponi AL, Raggio DP, Bönecker M. Associated factors to erosive tooth wear and its impact on quality of life in children with cerebral palsy. Spec Care Dentist. 2014 Nov-Dec;34(6):278-85. https://doi.org/10.1111/scd.12070

13. Murakami C, Tello G, Abanto J, Oliveira LB, Bonini GC, Bönecker M. Trends in the prevalence of erosive tooth wear in Brazilian preschool children. Int J Paediatr Dent. 2016 Jan;26(1):60-5.

14. Salas MM, Nascimento GG, Huysmans MC, Demarco FF. Estimated prevalence of erosive tooth wear in permanent teeth of children and adolescents: an epidemiological systematic review and meta-regression analysis. J Dent. 2015 Jan;43(1):42-50. https://doi.org/10.1016/i.jdent.2014.10.012

15. Lussi A, Jaeggi T. Erosion: diagnosis and risk factors. Clin Oral Investig. 2008 Mar;12(S1 Suppl 1):S5-13. https://doi.org/10.1007/s00784-007-0179-z

16. Jaeggi T, Lussi A. Prevalence, incidence and distribution of erosion. Monogr Oral Sci. 2014;25:55-73. https://doi.org/10.1159/000360973

17. Buzalaf MA, Hannas AR, Kato MT. Saliva and dental erosion. J Appl Oral Sci. 2012 Sep-Oct;20(5):493-502. https://doi.org/10.1590/S1678-77572012000500001

18. Hara AT, Zero DT. The potential of saliva in protecting against dental erosion. Monogr Oral Sci. 2014;25:197-205. https://doi.org/10.1159/000360372

19. Shitsuka C, Ibuki FK, Nogueira FN, Mendes FM, Bönecker M. Assessment of oxidative stress in saliva of children with dental erosion. Einstein (Sao Paulo). 2018 Jun;16(2):eAO4203. https://doi.org/10.1590/s1679-45082018ao4203

20. O'Brien M. Children's dental health in the United Kingdom 1993: report of dental survey: Office of Population Censuses and Surveys. London: Her Majesty's Stationery Office; 1994.

21. Leite MF, Ferreira NF, Shitsuka CD, Lima AM, Masuyama MM, Sant'Anna GR, et al. Effect of topical application of fluoride gel NaF 2\% on enzymatic and non-enzymatic antioxidant parameters of saliva. Arch Oral Biol. 2012 Jun;57(6):630-5. https://doi.org/10.1016/i.archoralbio.2011.10.022

22. Benzie IF, Strain JJ. The ferric reducing ability of plasma (FRAP) as a measure of "antioxidant power": the FRAP assay. Anal Biochem. 1996 Jul;239(1):70-6. https://doi.org/10.1006/abio.1996.0292

23. Brewer KJ, Murphy WR, Petersen JD. Synthesis and characterization of monometallic and bimetallic mixed-ligand complexes of iron(II) containing 2,2'-bipyrimidine or 2,3-bis(2-pyridyl)pyrazine. Inorg Chem. 1987;26(20):3376-9. https://doi.org/10.1021/ic00267a032

24. Rahman I, Kode A, Biswas SK. Assay for quantitative determination of glutathione and glutathione disulfide levels using enzymatic recycling method. Nat Protoc. 2006;1(6):3159-65. https://doi.org/10.1038/nprot.2006.378

25. Ferro PV, Ham AB. A simple spectrophotometric method for the determination of calcium. Am J Clin Pathol. 1957 Aug;28(2):208-17. https://doi.org/10.1093/ajcp/28.2_ts.208

26. Fiske CH, Subbarow YJ. The colorimetric determination of phosphorus. J Biol Chem. 1925;66:375-400. https://doi.org/10.1042/bj0260292

27. Tenovuo J. Salivary parameters of relevance for assessing caries activity in individuals and populations. Community Dent Oral Epidemiol. 1997 Feb;25(1):82-6. https://doi.org/10.1111/j.1600-0528.1997.tb00903.x

28. Wang P, Zhou Y, Zhu YH, Lin HC. Unstimulated and stimulated salivary characteristics of 12-13-year-old schoolchildren with and without dental erosion. Arch Oral Biol. 2011 Nov;56(11):1328-32. https://doi.org/10.1016/i.archoralbio.2011.04.013

29. Zwier N, Huysmans MC, Jager DH, Ruben J, Bronkhorst EM, Truin GJ. Saliva parameters and erosive wear in adolescents. Caries Res. 2013;47(6):548-52. https://doi.org/10.1159/000350361 
30. Kuriakose S, Sundaresan C, Mathai V, Khosla E, Gaffoor FM. A comparative study of salivary buffering capacity, flow rate, resting $\mathrm{pH}$, and salivary Immunoglobulin $\mathrm{A}$ in children with rampant caries and caries-resistant children. J Indian Soc Pedod Prev Dent. 2013 Apr-Jun;31(2):69-73. https://doi.org/10.4103/0970-4388.115697

31. Baumann T, Kozik J, Lussi A, Carvalho TS. Erosion protection conferred by whole human saliva, dialysed saliva, and artificial saliva. Sci Rep. 2016 Oct;6(1):34760. https://doi.org/10.1038/srep34760

32. Nagler RM, Klein I, Zarzhevsky N, Drigues N, Reznick AZ. Characterization of the differentiated antioxidant profile of human saliva. Free Radic Biol Med. 2002 Feb;32(3):268-77. https://doi.org/10.1016/S0891-5849(01)00806-1

33. Oakes LM. Sample size, statistical power, and false conclusions in infant looking-time research. Infancy. 2017 Jul-Aug;22(4):436-69. https://doi.org/10.1111/infa.12186 